\title{
O uso da
}

tecnologia/

metodologia

WebQuest

em práticas

pedagógicas no

contexto de uma

Licenciatura em

Letras/Espanhol

Raquel La Corte dos Santos

Recebido em: 29 de outubro de 2016

Aceito em: 06 de dezembro de 2016

Doutora em Letras (Língua Espanhola e Literatura Espanhola e Hispano-Americana) pela Universidade de São Paulo (2015) e Mestre em Linguística e Semiótica Geral também pela Universidade de São Paulo (2002). Atualmente é professora adjunta na Universidade Federal de Sersipe. Tem experiência na área de Letras, com ênfase em Letras, atuando principalmente nos seguintes temas: linguagens, letramentos, língua espanhola e uso das tecnologias no ensino $e$ aprendizagem de línguas.

Contato: ra.lacorte@smail.com 
PALAVRAS-CHAVE: metodologia; espanhol tecnologia; WebQuest;

Discutimos, neste artigo, o uso da tecnologia WebQuest em práticas vivenciadas na disciplina Metodologia do Ensino e Aprendizagem de Línguas, de um curso de Licenciatura em Letras/Espanhol. $\bigcirc$ objetivo da proposta era que os estudantes pudessem ampliar seus conhecimentos sobre metodologias (com foco no espanhol), melhorar seu nível de letramento digital e refletir sobre a apropriação social das tecnologias digitais no campo do ensino e aprendizagem de línguas. Nas aulas, partimos dos conhecimentos prévios dos alunos e da discussão de obras que tratassem sobre as principais metodologias de ensino e aprendizagem de línguas e de outras que abordassem, em linhas gerais, a questão do letramento digital e, em termos específicos, que versassem sobre a WebQuest. Para tanto, nos apoiamos nos trabalhos de Levy (2010), Xavier (2005) e Dias (2010), dentre outros. Os resultados alcançados foram a criação de WebQuests, o aprofundamento da reflexão sobre a importância do uso pedagógico de tecnologias e a melhora do letramento digital dos estudantes.

KEYWORDS: technology; In this article we discuss the use of Web Quest technology in some practices WebQuest; methodology; experienced in the discipline Teaching Methodology and Language Learning, Spanish offered by the course Language Arts (Spanish) at the Universidade Federal de Sergipe. Together with expanding their knowledge about language teaching methods, the aim of the project was that students could improve their level of computer literacy and could discuss social appropriation of digital technologies in the field of language teaching and learning. During the process, students could discuss texts that deal with the main language teaching methods as well as others that are concerned with the issue of digital literacy and specific terms that relate to WebQuests (Levy, 2010; Xavier, 2005; Dias, 2010; among others). The results achieved were the creation of WebQuests; the development of a deep reflection on the importance of the pedasogical use of technology in language teaching and the improvement of students' digital literacy. 
O USO DA TECNOLOgIa/METOdologia WEBQUEST EM PRÁticas PEDAGÓgICAS No CONTEXTO DE UMA

\section{INTRODUÇÃO}

Neste artigo, dialogaremos sobre uma prática pedagógica vivenciada no contexto de uma disciplina do curso de licenciatura em Letras/Espanhol da Universidade Federal de Sergipe, para a qual propusemos o uso de tecnologias digitais. Trabalhamos, particularmente, com a criação e uso da tecnologia/metodologia WebQuest, com o objetivo de: reunir e ampliar os conhecimentos dos alunos sobre metodologias do ensino e aprendizagem de línguas (com foco no espanhol); favorecer o letramento digital e outros letramentos; vivenciar, no fazer pedagógico, a questão da apropriação social das tecnologias digitais para o campo do ensino e aprendizagem de línguas.

Antes de relatar como essa experiência foi levada a cabo, retomaremos aqui, de forma muito resumida, alguns conceitos que circunscrevem a prática sociohistoricamente; são eles: técnica e tecnologia, cibercultura e ciberberesço, letramento e letramento digital. Em seguida, focalizaremos nossa atenção no conceito de WebQuest e trataremos do processo da prática pedagógica em si e seus resultados.

\section{TÉCNICAS E TECNOLOGIAS NO CAMPO DA EDUCAÇÃO E DO ENSINO E APRENDIZAGEM DE LÍNGUAS}

A educação, como uma área da vida social que comporta muitas e variadas práticas, há muito utiliza diferentes técnicas e tecnologias como instrumentos mediadores dos processos de ensino e aprendizagem. Para Rudiger (2007), cientista social que teoriza sobre técnica e tecnologias, o termo técnica designou, durante muito tempo, a arte de fazer algo ou um conjunto de diferentes atividades que envolvem conhecimentos práticos. Assim, por exemplo, se pensarmos no campo da educação, poderíamos dizer 
que seriam técnicas o falar em voz alta, a repetição de conceitos, a realizaçáo de atividades em dupla ou em grupos, bem como a escrita manual, a cópia, a tradução, os diferentes passos recomendados por determinados métodos de ensino, etc. Já o termo tecnologia, desde suas raízes, relaciona-se com a ideia de pensar sobre um fazer técnico, de sistematizar, de estudar.

Seguindo o pensamento de Rudiger (2007), é possível dizer que, na área do ensino e aprendizagem de línguas (Espanhol), circunscrita dentro do amplo campo da educação, as metodologias de ensino e aprendizagem podem ser consideradas como tecnologias, pois grande parte delas foram desenvolvidas a partir de teorias, de um pensar sobre determinadas técnicas e envolvem estruturas materiais. É o caso, por exemplo, do Método Audiolingual, que tinha como uma de suas bases teóricas pressupostos e experimentos oriundos da Psicologia da Aprendizagem e pressupunha o uso de aparelhos técnicos, tais como o gravador e o projetor de slides.

No entanto, é bom ter em mente que a relação entre técnica e tecnologia é complexa e que, muitas vezes, esses termos são usados um pelo outro, já que muitas técnicas são também fruto de estudos e sistematizaçóes. Como diz Levy: "Por trás das técnicas agem e reagem ideias, projetos sociais, utopias, interesses econômicos, estratégias de poder, toda a gama dos jogos dos homens em sociedade." (Levy, 2010, p.24).

Para Rudiger, já citado, o surgimento da tecnologia se relaciona com profundas mudanças sociais, econômicas e culturais que começam a despontar nas sociedades pré-industriais do final da Idade Média e início da Idade Moderna. Com a Revolução Industrial, a tecnologia passou a ser entendida como um desenvolvimento da técnica e da reflexão sobre a técnica. 
O uso da tecnologia/metodologia WEBQUeST EM PRÁticas PEdagógicas no CONTEXTo de uma

O autor mencionado vai falar de três estágios da expansão tecnológica. O primeiro começou com a Revolução Industrial (1750-1820) e o emprego da máquina para a exploraçáo de recursos naturais. $\mathrm{O}$ segundo se caracteriza pelo surgimento da eletricidade e dos sistemas fabris. E o terceiro seria marcado pela crescente automação daqueles sistemas e pelo surgimento de tecnologias capazes de programá-los através das linguagens artificiais.

Assim, para aquele autor, desde o século XIX até aos nossos dias, a tecnologia passou a ser a referência no mundo social histórico, em detrimento da religiáo, da política, da educação e da arte.

Em educação, os tipos de tecnologias empregadas permeiam desde a concepção de utilização dos espaços de aprendizagem, (por exemplo, o design de salas de aula), passando por concepçóes sobre os tipos de materiais que devem ser utilizados para alcançar determinados objetivos (giz, quadro negro, livro didático, CD, datashow, sites da Internet, etc.), o tipo de vestuário (o uso de uniformes, por exemplo) até as formas de comunicação do fazer pedagógico (oral, escrita, eletrônica e digital).

Segundo Kenski (2014), educação e tecnologias são indissociáveis:

A maioria das tecnologias é utilizada como auxiliar no processo educativo. Não são nem o objeto, nem a sua substância, nem sua finalidade. Elas estão presentes em todos os momentos do processo pedagógico, desde o planejamento das disciplinas, a elaboração da proposta curricular até a certificação dos alunos que concluíram um curso. (Kenski, 2014, 44)

Para a autora mencionada, a presença de uma determinada tecnologia pode induzir a profundas mudanças na maneira de organizar o ensino. 


\section{INTERNET E TECNOLOGIAS SURGIDAS COM O CIBERESPAÇO E A CIBERCULTURA}

Levy (2010) afirma que as tecnologias não são objetos autônomos, separados da sociedade e da cultura, pelo contrário estão investidas de projetos variados, com implicaçôes sociais e culturais. Ele crítica a metáfora tão disseminada de "impacto das tecnologias", pois para ele o impacto seria algo que viria de fora, algo comparado a um míssil, projétil ou pedra, algo do mundo frio das máquinas, alheio aos valores e significaçóes da vida humana. E, na verdade, não existiria impacto, pois as tecnologias (e/ou técnicas) seriam pensadas e produzidas pela sociedade e o uso intensivo de técnicas e tecnologias constituiria a humanidade enquanto tal.

A internet, tal como a conhecemos hoje, e o conjunto de dispositivos tecnológicos que dela fazem parte, não foram arquitetados com propósitos sociais e educacionais. Ao contrário, quando surgiu nos Estados Unidos, no início das décadas de 50 e 60, em plena guerra fria, a internet tinha objetivos militares, com vistas a alcançar superioridade tecnológica bélica em relação à ex União Soviética. Porém, nos anos 80, a internet passou a ganhar uma dimensão social com a expansão da participação, em seu desenvolvimento, de universidades e da contracultura norte-americana, representada, em parte, por jovens universitários interessados em tecnologia (os chamados hackers, os quais preconizavam a ideia de democratizaçáo do acesso às tecnologias, simbolizada, por exemplo, no slogan: "computer to the people").

Para Castells (2009), a internet nasce dessa improvável intersecção entre ciência, pesquisa militar e cultura libertária (a contracultura). O principal legado dessa cultura libertária foi o desenvolvimento da interconexão, em nível mundial, dos computadores que passou a propiciar o acesso a uma 
O USO DA TECNOLOgIa/METODOlogia WEBQUEST EM PRÁticas PEDAGÓgICAS No CONTEXTO DE UMA

quantidade enorme de informaçóes por parte de um número cada vez maior de pessoas e o compartilhamento em rede de ideias e de inovaçóes tecnológicas que estas ideias geravam. Levy (2010) vai chamar essa interconexão mundial de computadores de ciberespaço. Um espaço de comunicação aberto, plástico, fluido, formado por sistemas microeletrônicos de codificação digital. Segundo este autor, uma das principais funçóes do ciberespaço é o acesso a distância aos diversos recursos de um computador. O ciberespaço é o espaço virtual de uma nova forma de cultura a cibercultura.

Como afirma Lemos (2002), a cibercultura nasce no final do século XX com o que ele chama de "impactos socioculturais da microinformática". Segundo ele, o que vai marcar a cibercultura não é somente o potencial das novas tecnologias, mas uma atitude. Para o autor citado, a microinformática é resultado de dois acontecimentos importantes: um técnico - o desenvolvimento das tecnologias digitais e outro sociocultural: o movimento cyberpunk, com sua marca tecno-místico-anarquista. A atitude cyberpunk dá origem à cibercultura dos anos 80 e vai marcar todo seu imaginário.

Assim, a cibercultura, com a micro-informática, torna-se mais que o desenvolvimento linear da lógica cibernética, surgindo uma espécie de movimento social. A democratização dos computadores vai trazer à tona a discussão sobre os desafios da informatização das sociedades contemporâneas já que estes não só devem servir como máquinas de calcular e de ordenar, mas também como ferramentas de criação, prazer e comunicaçáo; como ferramentas de convívio. (LEMOS, 2002, 112). 


\section{LETRAMENTOS E LETRAMENTO DIGITAL NO ENSINO SUPERIOR}

Refletir sobre letramento digital nos remete a pensar tanto no termo letramento quanto no termo digital. Comecemos pelo termo digital. Do latim digitus - dedo - se referia, portanto, ao corpo físico, à matéria. Com o desenvolvimento da microeletrônica e do computador conectado à internet, digital passou a adquirir os significados advindos da nova era da informação e passou a ser relacionado com uma realidade imaterial, virtual. Assim o mesmo dedo que antes atuava junto à materialidade de uma folha de papel passa a atuar na imaterialidade do espaço tela do computador.

A discussáo sobre o letramento e letramento digital é bastante ampla, dialogaremos aqui com alguns autores com os quais nos afinamos sobre esses conceitos. Centremo-nos, inicialmente, no termo letramento. Soares (2002) lembra que o termo, vindo do inglês literacy, foi traduzido como letramento para explicar principalmente as práticas sociais de leitura e escrita. Soares (2002) diz que embora utilize em seu texto a palavra "conceitos", não haveria propriamente "conceitos" de letramento e sim diferentes ênfases na caracterização do fenômeno. Há autores que enfocam letramento como o conjunto das práticas sociais de leitura e escrita, há outros que fazem um contraste entre "letramento" e "alfabetização", diferenciando esta, que seria a aquisição da escrita por um indivíduo, ou grupo de indivíduos de letramento que seria a aquisição de um sistema escrito por uma sociedade dentro de um contexto sócio-histórico. Soares define letramento como estado ou condiçáo de quem exerce as práticas sociais de leitura e escrita. Com esse conceito em mente, a autora passa a analisar as novas práticas sociais de leitura e escritas favorecidas pelo advento do computador e da 
O USO DA TECNOLOGIA/METODOLOGIA WEBQUEST EM PRÁTICAS PEDAGÓgICAS NO CONTEXTO DE UMA

internet (web) e diz que vivemos um momento privilegiado para identificar o estado ou condição que estas novas práticas estão instituindo.

Para Xavier (2005), o surgimento e crescimento do uso de vários tipos de ferramentas tecnológicas fez surgir um novo tipo ou modalidade de letramento, o digital. Esse letramento considera a necessidade dos indivíduos de dominarem um conjunto de habilidades que devem ser trabalhadas com urgência pelas instituiçóes de ensino, a fim de capacitar o mais rápido possível os alunos a viverem como cidadãos neste novo milênio cada vez mais repleto de máquinas eletrônicas e digitais. Esse autor ainda afirma que:

O Letramento digital implica realizar práticas de leitura e escrita diferentes das formas tradicionais de letramento e alfabetização. Ser letrado digital pressupôe assumir mudanças nos modos de ler e escrever os códigos e sinais verbais e não-verbais, como imagens e desenhos, se compararmos às formas de leitura e escrita feitas no livro, até porque o suporte sobre o qual estão os textos digitais é a tela, também digital. (XAVIER, 2005, 2)

Pensamos que, para ser letrado digitalmente, o indivíduo precisa ter acesso ao mundo digital, ter acesso aos espaços digitais e participar das práticas sociais de leitura e escrita digital, mas antes precisa ter acesso aos espaços físicos que permitem transitar nos espaços digitais, precisa ter um computador ou acesso a um computador, conhecer um teclado, manipular um teclado para desenvolver habilidades psicomotoras. Parece muito básico pensar nisso, mas sabemos que ainda há um número grande de pessoas nessas condiçóes: são os excluídos digitais, daí a importância da inclusão digital. Estar excluído digitalmente, nos dias de hoje, é estar condenado a não fazer 
parte da maioria das atividades sociais que vão desde as econômicas até as socioculturais, pois, como afirmou o sociólogo espanhol Manuel Castells (2009), em uma entrevista, "a internet é o tecido das nossas vidas".

\section{A PROPOSTA DE USO DE TECNOLOGIAS NUM CURSO DE LICENCIATURA EM ESPANHOL: O CASO DA WEBQUUEST}

Agora procuraremos descrever e refletir sobre uma experiência ocorrida ao longo de uma disciplina que ministramos - Metodologia de Ensino e Aprendizagem de Línguas -, a qual é obrigatória para alunos que cursam a Licenciatura em Letras/Espanhol na Universidade Federal de Sergipe. Como parte do planejamento didático da disciplina, incluímos o uso da tecnologia/metodologia WebQuest. E o que é uma WebQuest?

Surgida na década de 90, nos Estados Unidos, já em pleno desenvolvimento da internet, podemos dizer que a WebQuest, doravante $W Q$, como conjunto de procedimentos e técnicas pensadas e sistematizadas para determinados objetivos, é uma tecnologia digital da era da internet e tem como propósito reunir conhecimentos de forma sistematizada sobre determinado assunto a partir de recursos da própria internet.

Ao acessarmos o site da WebQuest.org, encontramos a seguinte definição: "A webQuest é uma atividade investigativa onde as informaçóes com as quais os alunos trabalham provêm da internet." (tradução nossa) ${ }^{1}$

Para Hernández (2008, 4): "WQ é uma metodologia didática de aplicação racional das TIC (concretamente, da internet) na sala de aula, baseada no

1 No original: "A WebQuest is an inquiry-oriented lesson format in which most or all the information that learners work with comes from the web. 
O uso da tecnologia/metodologia WEBQUeST EM PRÁticas PEdagógicas no CONTEXTo de uma

construtivismo e nos princípios da aprendizagem cooperativa”. (tradução nossa) ${ }^{2}$

Dias $(2010,3)$ a define como "um ambiente virtual de aprendizagem colaborativa on-line que permite o desenvolvimento de projetos de pesquisa pelo uso da web e seus recursos".

A WQ tem uma estrutura fixa, possui, em geral, cinco partes: introdução, tarefa, processo, avaliação e conclusão; algumas possuem também a sessão recursos. A tarefa é a parte principal da $W Q$, pois representa a situação-problema que deverá ser solucionada a partir dos passos que serão seguidos, indicados no processo.

Entendendo como necessária uma pedagogia de inserção de tecnologias digitais tanto no planejamento como no desenvolvimento e em formas de avaliação de disciplinas de cursos universitários, propusemos o uso de diferentes tecnologias do ciberespaço ao longo da disciplina, porém priorizamos o trabalho de criação de $W Q$, que seriam construídas em grupo ao longo do curso. O objetivo da disciplina era apresentar aos alunos as principais metodologias de ensino e aprendizagem de línguas, a partir de um percurso histórico e motivar a discussão e reflexão crítica sobre os pontos favoráveis e desfavoráveis de cada metodologia em relação à aprendizagem de línguas. Assim, a proposta de uso de uma tecnologia que também é definida por alguns autores como método tinha o propósito de fomentar ainda mais a discussão sobre método e metodologias. As WQ a serem criadas pelos

2 No original: "WQ es una metodología didáctica de aplicación racional de las TIC (concretamente, de Internet) en el aula, basada en el constructivismo y en los principios del aprendizaje cooperativo.". 
alunos teriam pelos menos duas funçôes: a de contribuir para a aquisição e aprofundamento de conhecimentos sobre determinadas metodologias de ensino e aprendizagem de línguas e a de contribuir para a melhoria do letramento digital (e/ou aquisição de outros letramentos) dos envolvidos no processo pedagógico.

Assim, antes de propor aos alunos como processo de aprendizagem e também como instrumento de avaliação a criaçáo de WQ; preparamos algumas aulas expositivas nas quais apresentamos um panorama geral das metodologias pensadas para o ensino e aprendizagem de línguas; discutimos em sala de aula alguns textos e somente depois fizemos a organizaçáo dos grupos.

Introduzimos a proposta de criação de $W Q$ no planejamento da disciplina e, na primeira aula, passamos um questionário aos alunos para procurar saber o nível de seu letramento digital. Foi um questionário com onze perguntas, dentre elas algumas que procuravam saber quais recursos da internet os alunos conheciam que teriam utilidade para o aprendizado e ensino de línguas e se os alunos conheciam a $W Q$. Algumas dessas perguntas foram:

1. Quais recursos da internet você utiliza no seu cotidiano e com que objetivo?

2. Utiliza a internet com o objetivo de aprender espanhol? Quais recursos utiliza?

Já ouviu falar em $W Q$ ? Conhece alguma? Qual? 
O USO DA TECNOLOgIa/METODOlogia WEBQUEST EM PRÁticas PEDAGÓgICAS No CONTEXTO DE UMA

3. Você se sente letrado digitalmente? Há algum recurso que você gostaria de saber utilizar?

4. Gostaria de sugerir o uso de algum recurso da internet, que você considera interessante para a aprendizagem de línguas (espanhol)?

Após a análise das respostas dos alunos, descobrimos que na sala havia alguns poucos alunos (apenas cinco de um grupo de vinte e cinco) que tinham tido experiência no uso de $W Q$ e outros que conheciam recursos que poderiam ser usados para a aprendizagem de línguas. Dessa forma, a grande maioria dos alunos não tinha nenhum conhecimento sobre $W Q$ nem sobre recursos que pudessem ser usados para aprender línguas. Uma parte dos alunos, inclusive, tinha dificuldade em buscar e selecionar informações na internet.

Acreditando que juntos se aprende mais e que o que os alunos podem aprender sozinhos é diferente do que podem aprender quando interagem com colegas mais experientes, inspirando-nos no clássico conceito de Vygotsky (1988) de Zona de Desenvolvimento Proximal (ZDP) que ressalta a importância na aprendizagem da interação com o par mais experiente, dividimos os grupos de forma que, em cada um deles, houvesse alunos melhor letrados digitalmente.

Cada grupo escolheu aprofundar determinada metodologia a partir de pesquisas que seriam feitas na internet; os alunos deveriam consultar diferentes sites, reunir uma quantidade de informaçóes, selecioná-las e depois e reuni-las na $W Q$. Passamos a organizar as aulas como oficinas de preparação das $W Q$. Para isso, reservamos o laboratório de línguas no qual 
os alunos teriam acesso à internet e passamos a orientar os trabalhos, ficando à disposição dos alunos para esclarecer dúvidas; indicar alguns caminhos; fomentar o senso crítico para a seleçáo e filtragem de informaçóes e materiais que seriam utilizados na $W Q$.

As práticas em grupo para o desenvolvimento das $W Q s$ tinham dois objetivos: que os alunos adquirissem conhecimentos mais profundos sobre determinada metodologia e que, ao mesmo tempo, desenvolvessem seu nível de letramento digital. A própria $W Q$, por estar constituída no ciberespaço e fazer uso das possibilidades do ciberespaço, propiciaria aos alunos o acesso a um conjunto de novas tecnologias; o que poderia ampliar seu letramento digital.

Os alunos foram divididos em cinco grupos e escolheram trabalhar com as seguintes abordagens metodológicas: Audiolingual; Comunicativa; Contemporânea a partir da noção de multiletramento; Contemporânea intercultural e do Ensino de Lìnguas para Fins Específicos.

Para favorecer as práticas e facilitar o acesso aos alunos que não tinham internet ou que tinham internet de baixa qualidade, optamos por realizar as aulas no Laboratório de Línguas, assim os alunos poderiam acessar sites que versassem sobre as metodologias escolhidas; começar a criar, discutir, interagir e negociar entre si os conteúdos de cada parte da WQ. Foram definidos critérios de avaliação das $W Q$. Os grupos deveriam trabalhar por etapas e, a partir de um cronograma pré-definido, nos enviar, por e-mail, cada etapa finalizada para avaliação.

Com as práticas de construção das $W Q$, os alunos puderam organizar o conhecimento sobre determinada metodologia e reunir um conjunto de 
O USO DA TECNOLOgIa/METODOLOGIA WEBQUEST EM PRÁTICAS PEDAGÓGICAS NO CONTEXTO DE UMA

informaçóes extraídas das leituras online de artigos disponíveis em diferentes sites e de outras fontes de informação como vídeos do Youtube e outras.

Dessa forma, os alunos estiveram expostos a diferentes linguagens e modos de representação (visuais, sonoros, gráficos) e aprenderam, uns com os outros, técnicas de como inserir informaçóes, links, vídeos e imagens na $W Q$, ou seja, puderam exercer a condição de quem participa das práticas de letramento digital (Soares, 2002).

Para ilustrar, copiamos algumas imagens de uma das $W Q$ criadas pelos alunos, nas quais podemos notar o uso de diferentes dispositivos da internet, o que manifesta diferentes letramentos em andamento. Na Figura 1, temos a Introdução (primeira parte) da $W Q$ : Abordagem Comunicativa. Aparecem na aba os títulos de cada parte da WQ e, quando clicamos em cima dos títulos, abre-se uma janela e temos acesso às informaçôes de cada título. Essa simples ação, que revela um letramento informático, esteve presente ao lado de outros letramentos. O grupo precisou aprender como inserir títulos que funcionassem como âncoras (GOMES, 2010) de seus conteúdos. Neste sentido, os alunos vivenciaram tanto a leitura na Web quanto a produção de textos e hipertextos. Na Figura 2, temos a segunda parte da WQ do grupo Metodologia Comunicativa. Nessa parte, o tema tratado pelo grupo foi a tarefa. A abordagem foi feita de forma lúdica (como uma caça ao tesouro); o grupo listou uma série de missóes, as quais deveriam ser cumpridas para finalizar a tarefa. 


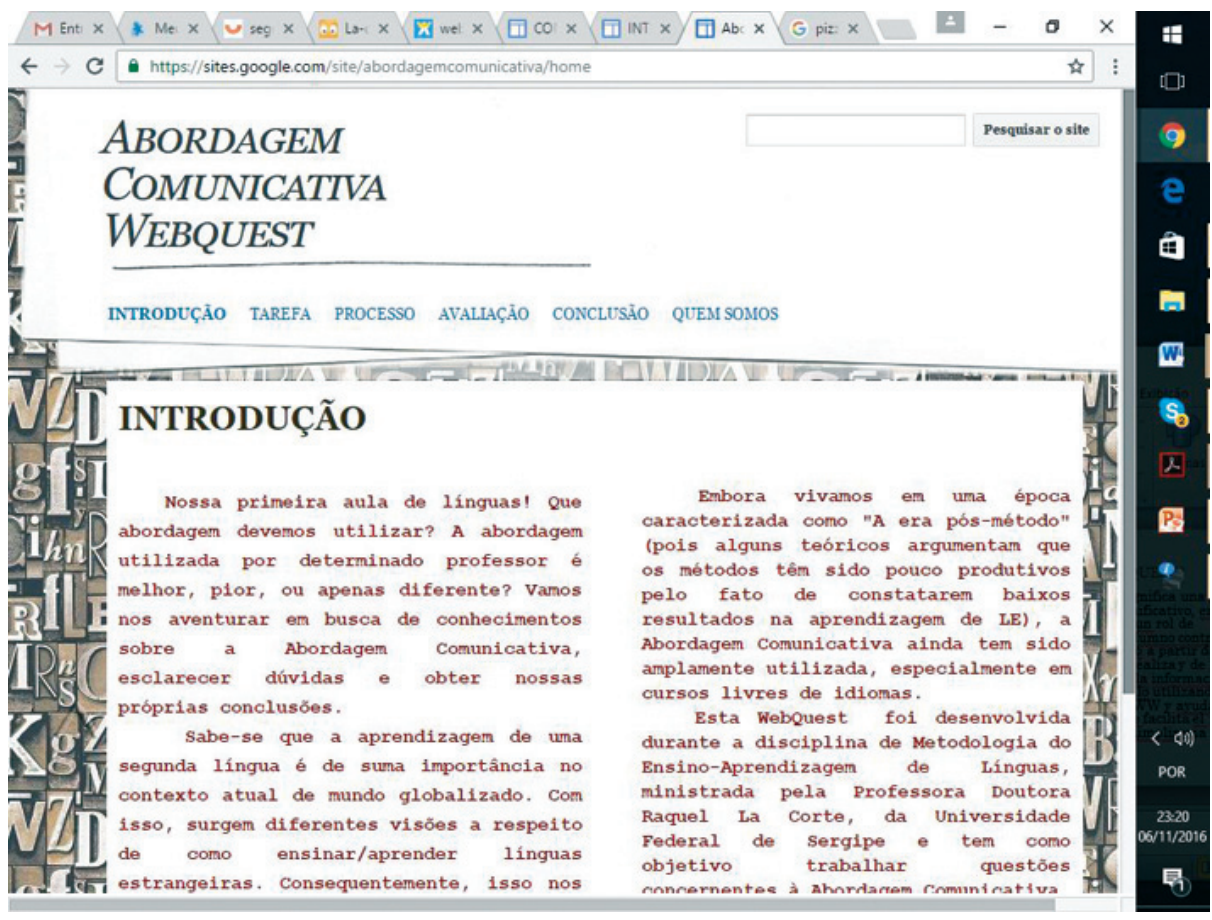

Figura 1: PrintScreen de tela da internet - Abordagem Comunicativa: Introdução

A tela que pudemos inserir aqui representa um recorte da original, onde aparece uma introdução às missões, uma explicação sobre a proposta da caça ao tesouro e a informação de que o tesouro são os conhecimentos que o leitor poderá adquirir sobre a Metodologia Comunicativa. Há um total de sete missões e estas incluem o acesso a um vídeo do Youtube. Para realizar as missôes e encontrar o tesouro, o grupo criou, na parte Processo (figura 3), um conjunto de "pistas": 


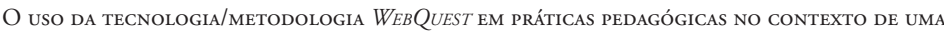
Licenciatura EM LeTras/Espanhol

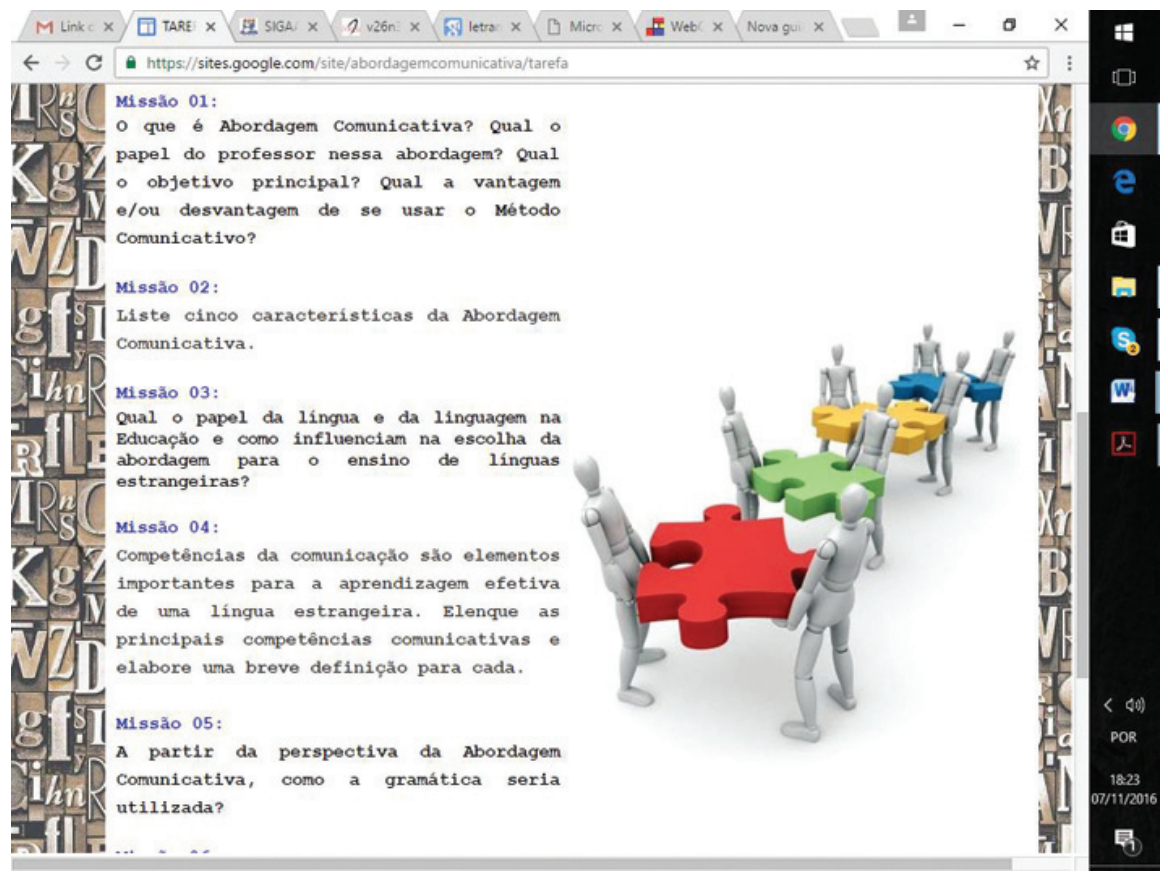

Figura 2: PrintScreen de tela da Internet - Abordagem Comunicativa: Tarefa

Na Figura 3, observamos que o grupo aprendeu a inserir âncoras que nos remetem não somente aos textos internos da própria $W Q$, mas também a várias páginas da internet que dizem respeito à Metodologia Comunicativa. Podemos notar que os links remetem a textos de variadas fontes e incluem desde textos da Wikipedia e artigos científicos até um texto preparado pelo próprio grupo ${ }^{3}$. Além disso, podemos observar na Figura 3, na parte

3 O texto em questão tratava da Metodologia Comunicativa e foi resultado de uma atividade desenvolvida na disciplina, que consistia em uma produção coletiva dos alunos no google.docs. 
inferior, que o grupo aprendeu também a disponibilizar para o leitor textos para download.

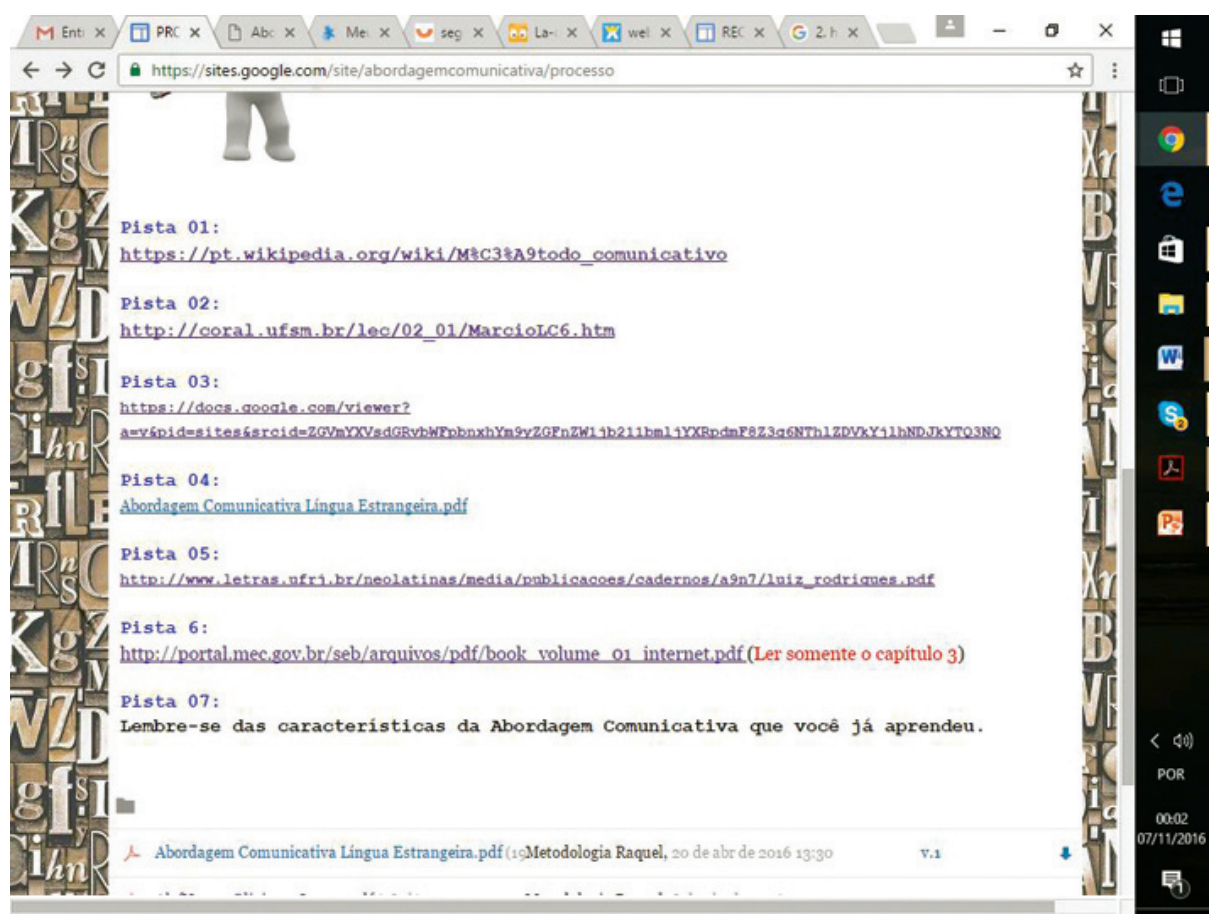

Figura 3: PrintScreen de tela da Internet - Abordasem Comunicativa: Processo.

A Figura 4 corresponde à primeira parte da WQ de outro grupo, o quela trabalhou com a temática do ensino de línguas para fins específicos. Nessa $W Q$, o título de cada parte também funciona como uma âncora que, por meio de um click, remete ao conteúdo correspondente. Um aspecto que chama a atenção é a apresentação visual e o manejo dos aspectos gráficos: o uso de cores, o tamanho e tipo de letras e uso de diferentes formas. 


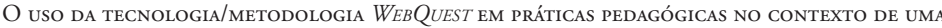

Licenciatura em Letras/Espanhol

Raquel La Corte dos Santos

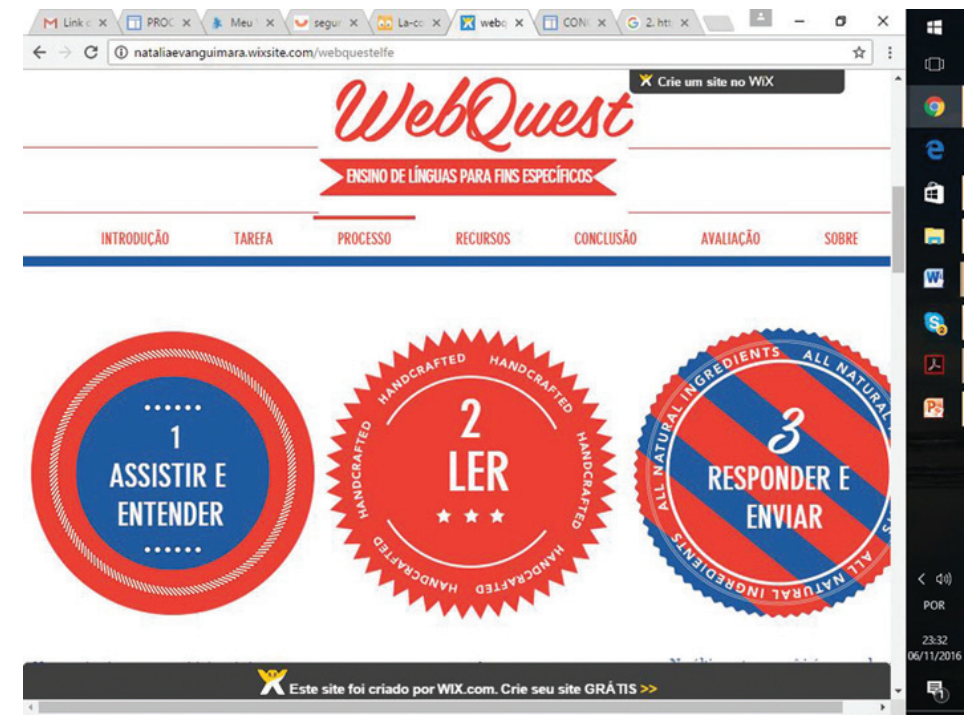

Figura 4: PrintScreen de tela: Ensino de Línguas para Fins Específicos.

Ao final da criação das $W Q$, com todas as partes desenvolvidas, os alunos apresentaram suas produçóes para toda a sala e compartilharam os links das WQ para que todos pudessem ter acesso ao seu conteúdo. Houve uma ampla conversa para discussão sobre as estratégias que cada grupo tinha feito para conseguir desenvolver sua $W Q$. Além desse aprendizado do fazer tecnológico, os estudantes afirmaram que aprenderam muito sobre a metodologia que escolheram como conteúdo de sua $W Q$.

\section{CONSIDERAÇÕES FINAIS}

O primeiro aspecto que chamou-nos a atenção ao fazer a proposta de uso da WQ como um instrumento de aprendizagem foi a boa aceitaçáo 
dos alunos, mesmo por parte daqueles que náo participavam dessas práticas de letramento ou que se sentiam excluídos digitalmente. Alguns manifestaram temor de náo conseguir realizar a tarefa de construção da WebQ. No entanto, em grupo, todos conseguiram realizá-la e, ao final das produçóes, demonstraram satisfação por haver alcançado os objetivos da tarefa. Reproduzimos a seguir alguns comentários feitos pelos alunos ao final do processo, após entrega e compartilhamento dos links das $W Q$.

Comentário 1. A webquest é algo que vai servir de referência a partir de agora. Afinal de contas, está aí, online, para acesso a qualquer hora.

Comentário 2. Trabalhar com a webquest foi ainda mais diferente, pois era um recurso totalmente novo, que não tínhamos conhecimento do seu funcionamento ou criaçáo. Tratar sobre metodologias do ensino de línguas, seu desenvolvimento e características foi um trabalho interessante de pesquisa para encaixa-lo dentro do formato da webques.

Comentário 3. Se tratando da WebQuest, foi uma experiência incrível! É uma ferramenta ótima que pode ser utilizada pra trabalhar todo e qualquer tema. Achei que seria difícil o trabalho de criar uma, mas não foi. Amei produzi-la, e particularmente, fiquei muito satisfeita com o resultado final.

Para desenvolver uma $W Q$, os alunos tiveram que fazer uso de diferentes dispositivos da internet, o que possibilitou conhecer novos materiais, recursos disponíveis na rede, recursos bibliográficos que lhes permitiram explorar e aprofundar os conteúdos.

$\mathrm{O}$ fato de terem que investigar online em vários sites, selecionar informaçōes, aprender a organizar as informaçóes na $W Q$, aprender a inserir âncoras, vídeos e imagens fez com que os alunos desenvolvessem 
O uso da tecnologia/metodologia WEBQUeST EM PRÁticas PEdagógicas no CONTEXTo de uma

o letramento digital e, também, múltiplos letramentos (de leitura digital, informático, visual, gráfico, etc.).

Como licenciandos e futuros professores, a experiência foi muito proveitosa porque, ao pesquisar para a $W Q$, tiveram acesso a atividades de aprendizagem, a dispositivos multimídias pensados para a aprendizagem, a banco de dados, a sites de instituiçôes de ensino, o que contribuiu também para o seu letramento acadêmico.

Essa prática pedagógica de desenvolvimento e uso da tecnologia/ metodologia WebQuest numa disciplina da licenciatura em Letras/Espanhol abriu a possibilidade de autoria aos alunos em ambiente virtual, pois passaram de consumidores de informaçáo a produtores. Coube a eles a decisão de como queriam que fosse a $W Q$, bem como a responsabilidade pela busca de textos, imagens ou material multimídia, a seleção e escolha desses materiais, a definição do formato da $W Q$ e a escrita dela. Os alunos foram protagonistas do processo e de sua própria formação.

\section{REFERÊNCIAS BiBLIOGRÁFICAS}

Buzato, Marcelo El Khouri. Letramentos Digitais e Formação de Professores. São Paulo: Portal Educarede, 2006.

Castells, Manuel. Sociedade em rede - A era da informática: economia, sociedade $e$ cultura. v. 1. São Paulo: Paz e Terra, 2009.

Dias, Reinildes. "Webquests no processo de aprendizagem de L2 no meio on-line". In: Paiva, Menezes, Vera Lúcia (Org.). Interação e aprendizagem em ambiente virtual. 2 ed. Belo Horizonte: Editora UFMG, 2010, p. 359-394.

Gomes, Luis Fernando. Hipertextos multimodais: leitura e escrita na era digital. Jundiaí (SP): Paco Editorial, 2010. 
Kenski, Vani Moreira. Educação e Tecnologias: o novo ritmo da informação. Campinas (SP): Papirus, 2014.

Lemos, André. Cibercultura: tecnologia e vida social na cultura contemporânea. Porto Alegre: Sulina, 2002.

Lévy, Pierre. Cibercultura. Trad. Carlos Irineu da Costa. São Paulo: Editora 34, 2010.

Mercedes, María del Pilar Hernández. Tareas Significativas y recursos en Internet: WebQuest. MarcoELE. Revista de didáctica ELE. núm. 6, 2008.

Rudiger, Francisco. Introdução às teorias da cibercultura. Porto Alegre: Sulina, 2007.

Soares, Magda. Letramento: um tema em três gêneros. Belo Horizonte: Autêntica, 2002.

Xavier, Antonio Carlos dos Santos. Letramento digital e ensino. In: Ferraz, Carmi e Mendonça, Márcia (Orgs.) Alfabetização e Letramento: conceitos e relaçóes. Belo Horizonte: Autêntica, 2005, p.133-148.

Vygotsky, Lev Semenovitch. A Formação Social da Mente. São Paulo, Martins Fontes, 1988 . 